\title{
INTERVENÇÃO, EXPERIÊNCIA E PRODUÇÃO DE SABERES ${ }^{1}$
}

\author{
Yves Schwartz ${ }^{2}$
}

\section{RESUMO}

Neste artigo discutimos, na perspectiva da ergologia, em que consiste ir "ao encontro" das atividades humanas, das atividades de trabalho e, mais geralmente, de todas as atividades sociais. O caso do trabalho dentro do setor "social” evidencia particularmente o problema. Isso é feito pondo em questão a tendência permanente de subestimar o trabalho de "tratamento dos encontros" nas atividades de trabalho. Acreditamos que haja uma dimensão genérica das questões que nos são postas aqui a propósito do que temos chamado de "tratamento do encontro". Indagamo-nos sobre a especificidade dos “encontros” na atividade de trabalho do Serviço Social na Saúde. Neste ofício a atividade de trabalho real pressupõe ir ao encontro de uma extrema diversidade de maneiras de viver e de sobreviver, numa prodigiosa e, às vezes, dolorosa engenhosidade na forma de produzir a vida. Esse tratamento do encontro se apresenta, então, como um apelo a captar os saberes sob a injunção, mais ou menos interiorizada de cada assistente social, dos valores de saúde e de cidadania. É um verdadeiro trabalho, que aparece como um paradigma "explosivo" das questões mais fundamentais que estão postas hoje, relativas à epistemologia e à deontologia dos conhecimentos das atividades humanas.

PALAVRAS-CHAVE: Trabalho, Ergologia, Serviço Social, Saúde Pública

\section{QUESTÕES DE « ENCONTROS »}

Refletindo sobre a contribuição que, para minha honra, solicitam-me, pareceu-me que a atividade peculiar do Serviço Social, aqui no Brasil, permitiria que se reconstruísse sobre esse tópico em particular uma questão que nos é proposta de forma

\footnotetext{
${ }^{1}$ Conferência proferida sob o título «Intervention, expérience et production de savoirs»: Questions de «rencontres » apresentada no IV Congresso Nacional de Serviço Social na Saúde da USP, UNICAMP e UNESP - CONASSS 2008 - Campinas, em 11 de junho 2008. Tradução de Cristian Vieira e revisão técnica de Edna Maria Goulart Joazeiro.

${ }^{2}$ Filósofo, Membro do Institut Universitaire de France (IUF), Professor Emérito do Institut d'Ergologie da Université Aix-Marseille - França.
} 
recorrente: por que, entre o percurso ergológico desenvolvido há mais de vinte anos na França e os esforços, as experiências e as iniciativas implantadas em longo prazo por numerosas equipes de colegas e de amigos, aqui no Brasil, há tanta convergência, trocas mútuas e cooperação em clima de confiança?

Nosso percurso ergológico, na universidade, insiste, fundamentalmente, na necessidade de fazer nosso ofício ir "ao encontro" das atividades humanas, das atividades de trabalho e, mais geralmente, de todas as atividades sociais. Pois então, parece-me que essa exigência é largamente compartilhada e estabelecida por todos os amigos brasileiros com os quais trabalhamos e, sem dúvida, por razões que trazem características próprias deste grande país. Ter conhecimento e fazer amizade com este país, enfim, é ir ao encontro de uma extrema diversidade de maneiras de se viver e de se sobreviver, uma prodigiosa e, às vezes, dolorosa engenhosidade na forma de se produzir a vida. País esse de extrema diversidade e desigualdade, geográfica, étnica e econômica, onde as formas coletivas de atividade industriosa, rurais e urbanas, alimentam saberes, tradições e valores que distinguem profundamente as diversas camadas da população.

Portanto, o Brasil vive, assim, sua história e, interpretando-se essas diferenças somente em termos de graus de insuficiência, de desigualdade, em matéria de cultura, de saberes, de projetos construtores de vida, não se compreenderia, sem dúvida, como o Brasil “é possível”. Será que encontrar o Brasil seria somente encontrar uma escala contínua que localizaria populações, famílias e indivíduos, com respeito a sua distância relativa do trabalho dito "formal”, e em relação a uma alfabetização e uma educação completa, a um conforto e a uma habitação corretos? Esse leque de desigualdades nos remete a um polo único de referência e de avaliação? Ou se faz necessário, também, procurar-se decifrar construções de saberes, reservas de 
potencialidades ou de alternativas de débil visibilidade? Não há, também, o que se aprender com esse encontro? É sobre este tema que eu gostaria de situar minha proposta: o que fazer desse encontro? Um encontro que parece estar no coração das tão complexas profissionalidades do Serviço Social. “O que fazer desses encontros?” O diálogo, como encontro dos homens para a tarefa comum de saber agir, se rompe, se seus polos (ou um deles) perdem a humildade (FREIRE, 2007, p. 93).

Esse propósito de Paulo Freire, como dezenas de outros em sua obra, poderia sintetizar a fortíssima convergência inicial entre a perspectiva ergológica e o que há de mais fecundo, intelectual e eticamente, no encontro com uma herança característica da história brasileira recente. O encontro é uma tarefa deontológica e ética à qual todo saber deve se propor. Mas no caso do ofício do Serviço Social, ele não tem que se “propor”, ele é de fato, a substância mesmo desse ofício. Então, a questão que se põe, simplesmente, é: o que se faz desse encontro?

\section{O SERVIÇO SOCIAL NA SAÚDE: QUAL É A ESPECIFICIDADE DESSES ENCONTROS?}

Em um belo e sintético artigo, a senhora professora Maria Lúcia Martinelli insiste no fato de que o Serviço Social é uma profissão “de natureza eminentemente interventiva” que age no campo das relações humano-sociais (2007, p. 22-3). “Intervenção”: o que quer dizer? Qual é a disposição dos profissionais do Serviço Social quando esses se propõem ou se impõe a agir diante dos usuários? Estando eles, frente a esses usuários, se colocam como se estivessem diante de “coisas” sobre as quais se aplicam instruções e regras correspondentes a situações-tipo? Situações tipo nas quais se faria entrar tais usuários, como se estivessem em uma caixa? Ou, ao contrário, tais 
usuários são vistos como pessoas que levam consigo retalhos de história e complicadas combinações de trajetória de vida entregues à decifração da assistente social?

A professora Martinelli responde a essa questão em dois parágrafos, nos quais se pode encontrar a substância própria de todas as dificuldades, mas também os apelos feitos à "humanidade” dos profissionais de tais serviços:

É isso que nos pede a ética da proteção social como direito, como elemento fundante da cidadania, lembrando-nos da importância de se captar as diferenças sociais, as necessidades dos usuários, mas também as suas capacidades, que podem ser desenvolvidas tanto no contexto hospitalar quanto em sua própria comunidade através das redes de apoio, o que é fundamental para sua proteção e autonomia.

O alcance do olhar do profissional eticamente comprometido transcende os muros do hospital, buscando os núcleos de apoio na família, na comunidade, lugares sociais de pertencimento onde se dá o cotidiano de vida das pessoas. É na cotidianidade da vida que a historia se faz, é aí que se forjam vulnerabilidades e riscos, mas se forjam também formas de superação (MARTINELLI, 2007, p. 28).

Eis alguns propósitos notáveis: as “diferenças” (“diferenças sociais”) são em parte, também, a substância da mensagem de Paulo Freire, não são “resíduos” para a profissional assistente social, mas, sim, apelos a se aprender: não há nada de passivo no encontro com essas diferenças. Pelo contrário, há uma convocação a “captar”, a "buscar” o que a vida fez desses usuários e o que esses tentam fabricar a partir de sua condição de vida. Uma busca que deve ir além dos muros do hospital, à procura de “tijolos” construídos na cotidianidade, nas famílias, nas comunidades; tentar aprender com a humildade evocada por P. Freire, em todos esses lugares relevantes onde "se faz a história” (“onde a história se faz”), e não somente através da vulnerabilidade, mas, Revista Serviço Social \& Saúde. UNICAMP Campinas, v. X, n. 12, Dez 2011 
também, das formas de superação desta vulnerabilidade, o que, em nossa linguagem ergológica, chamamos de "reservas de alternativas”. Tal investigação se fará ainda mais atenta e exigente quando ancorada nas normas de vida desses profissionais, num par de valores: a saúde e a cidadania. Valores que não têm conteúdo perfeitamente definido, estabilizado, o que não impede de serem, dentro da singularidade própria dos profissionais desses serviços, matrizes fortíssimas de exigências operacionais.

Esse tratamento do encontro se apresenta, então, como um apelo a captar os saberes sob a injunção, mais ou menos interiorizada segundo cada assistente social, dos valores de saúde e de cidadania. A senhora Edna Goulart, na tese que acaba de defender, sob a Supervisão de Estágio em Serviço Social, na Faculdade de Educação da UNICAMP, sob a orientação da senhora professora Maria Inês Rosa, exprime fortemente o que se dá, no encontro de tal forma definido, ao nível das dinâmicas de saberes: um trabalho extremamente afiado de articulação entre as regras gerais construídas no processo de profissionalização da profissão e uma extrema disponibilidade intelectual diante dos casos singulares que porta cada usuário.

A estudante-estagiária, ao se deparar com uma situação de atendimento onde são requeridos saberes disciplinares referentes às questões do usufruto do direito, é convocada a gerir os seus conhecimentos no cuidado com outrem, o usuário do Sistema Público de Saúde (JOAZEIRO, 2008, p. 144).

Para lidar com esse encontro, então, ela precisa, em tal momento:

[...] reconvocar esses saberes para realizar o atendimento. Ela busca, no atendimento face a face, a relação entre uma situação singular, a história de uma pessoa, correlacionada com o conhecimento da norma antecedente do direito previdenciário, trabalhista, civil ou sucessório (Ibid, p. 144). 
Desse ponto de vista, quer seja a estagiária, quer seja a supervisora, o problema é o mesmo, um empréstimo necessário dos saberes gerais do ofício, porém, retrabalhados, e reunido em nome do encontro da singularidade das pessoas a se assistir.

Trata-se de um percurso a se realizar que se fundamenta na norma antecedente e que requer uma ressingularização em função das especificidades de cada situação que traz, ao mesmo tempo, aspectos gerais, singulares e particulares (JOAZEIRO, 2008, p. 144).

Trata-se, então, de um “encontro entre sujeitos históricos”: é impressionante ver como a senhora Edna Goulart insiste no tema do encontro:

Ressalta-se que os encontros são em parte singular, onde a protagonista da atividade se confronta com situações heterogêneas, complexas, nas quais o risco de vida, a escassez de recursos, a presença da doença e o medo da morte marcam, a rigor, a necessidade de decisões situadas no tempo e no espaço (Ibid., p. 145).

Assim, a experiência e as microescolhas de gestão das situações se ancoram em um patrimônio de saberes acumulados e regulados por coerências internas "nascidas de encontros fecundos entre normas antecedentes da profissão e da saúde” (Ibid., p. 145). Dessa forma, tem-se que o saber pertinente para se tratar a situação é um saber “datado”, que deve ser, para fazer sentido na situação singular do aqui e agora, de acordo com esta bela expressão: “esmiuçado” (Ibid., p. 145).

Em outros termos, a atividade de "captação", de acordo com a expressão da senhora Lúcia Martinelli, supõe uma dupla manipulação sobre os saberes:

- decompor para rearticulá-los de maneira diferente os saberes profissionais até então organizados e fechados sobre sua própria coerência disciplinar; 
- e isso sob a coerção da aprendizagem das formas, sempre parcialmente ressingularizadas, segundo as quais os usuários tentam construir sua vida social.

Assim, o encontro que a profissional do Serviço Social na Saúde deve ter com uma pessoa, sua família (ou a ausência da família), a comunidade à qual pertence, enfim, conduz essa profissional a procurar e a convocar certos elementos do direito assistencial e do direito trabalhista, elementos que ela deve articular com os conhecimentos apreendidos relativos a tal adoecimento, às diversas terapêuticas que permite tratar e aos prognósticos de cura relacionados. E isso com um olhar sobre aquilo que se pode antecipar a respeito das condições objetivas da vida da pessoa, levando-se em conta seus recursos, sua habitação, seu bairro, sua favela...

Todavia, mesmo nessas convocações “esmiuçadas” de fragmentos de saberes já formalizados, nada é mecânico: a profissional assistente social deve se interrogar, se colocar em situação de aprendizagem relativa às questões: de que forma essa família, essa comunidade, no limite de seus recursos, é suscetível de se organizar para tratar de tal doença que afeta um dos seus ${ }^{3}$ ? Quais são as dimensões de vulnerabilidade desses grupos sociais e quais são, ainda, suas “formas de superação”, segundo a palavra da professora L. Martinelli.

Esses questionamentos e essa disponibilidade de aprendizagem sobre as formas de "superação” orientam os empréstimos que deve fazer a profissional junto aos elementos do saber acadêmico sobre o direito, a saúde, a demografia, a sociologia urbana...

\footnotetext{
${ }^{3}$ Há escolhas a fazer, "devido ao fato de a assistente social intervir junto da família, tendo por objetivo articular, ou seja, empreender relações sinérgicas entre os diversos serviços existentes quer no âmbito do município de moradia do usuário, quer no âmbito regional. E o faz com vista a permitir condição material para viabilizar a continuidade do tratamento tanto quanto para permitir a recuperação da saúde, como, ainda, para amenizar o seu sofrimento" (JOAZEIRO, p. 120). Ver também p. 130, § 3. 
Assim, pode-se citar o propósito de uma supervisora ressaltada por Edna Goulart:

Então, você precisa ir conhecendo um pouco das doenças [...]. Não digo deter um conhecimento, mas um mínimo. Então, você tem necessidade de conhecimentos específicos sobre as doenças, sobre algumas coisas a respeito dos medicamentos e, aí, vêm as políticas de saúde. Das políticas de saúde, até a academia pode dar conta, não é? Mas para você chegar às políticas de saúde, você tem que entender quem é o doente, que história ele vivencia. Isso é específico nosso, da saúde! (JOAZEIRO, 2008, p. 141).

A relação com a história, no encontro com “quem é o doente”, especifica a relação com a saúde, com o conhecimento da Medicina e o da saúde pública do profissional do Serviço Social na Saúde. Consequentemente, essa forma de captaçãoempréstimo, essa forma de reunião dos saberes em face das ressingularizações parciais dos jeitos de se viver é, por isso, definitivamente, não antecipável. Não há regras gerais para se "buscar coadunar os saberes do corpus do conhecimento da profissão com os saberes nascidos da atividade (E. Goulart, op. cit., p. 127)”. É necessário, a cada vez, fazer o uso de si mesmo para se reconstruir a articulação dos saberes procedentes da experiência dos encontros e aqueles já formalizados no corpus disciplinar. Pedagogicamente, isso faz toda a diferença entre "formar" e "treinar", segundo uma distinção de Maria Inês Rosa (2004), entre um treinamento que se baseia unicamente na hipótese da antecipação dos encontros pelos protocolos e uma formação que prepara para o encontro com os usos de si, algo nunca precisamente antecipável, diante dos usuários.

Visto assim, o tratamento do encontro é um verdadeiro trabalho. Se se tratasse apenas de se aplicar as regras, tal tratamento teria qualquer coisa de mecânico. Revista Serviço Social \& Saúde. UNICAMP Campinas, v. X, n. 12, Dez 2011 
Dado ser necessário hibridar elementos de saberes existentes a partir das questões que traz o encontro, nunca exatamente idênticas à precedente, então, há um uso de si por si mesmo que jamais é abandonado, trata-se de um apelo à memória seletiva e à sua capacidade de escolher, enfim, um trabalho sobre os recursos possíveis. Encontro imprescritível, para os estudantes-estagiários estudados por Edna Goulart, é

[...] o da conjugação entre os saberes epistêmicos, os saberes científicos da formação da supervisora e da estudante-estagiária, e de outro, os saberes da disciplina ergológica requeridos para realizar a atividade de atender o usuário, ou, seja o encontro imprescritível a ser realizado com o doente, com sua família ou com os profissionais de diversas áreas de conhecimento que estão envolvidos no processo de cuidado do usuário (JOAZEIRO, op. cit., p. 113).

Por si só, consequentemente, tem-se um trabalho sobre si mesmo ${ }^{4}$ : se o valor “saúde” (relativo aos outros), se o valor “co-cidadania” (relativo ao usuário) são indiferentes, que qualidade terá tal trabalho? Fazer esse trabalho, em função do peso que se dá a esses valores, é, também, uma escolha do que queremos ser. Humanizando nossa prática profissional, diz a senhora L.Martinelli, “fortalecemo-nos enquanto seres humanos” (2007, p. 22).

Há, pois, uma relação estreita, frequentemente subestimada ou tão simplesmente ignorada, entre nossa ligação com o mundo dos valores e nossa maneira de trabalhar os saberes: para citar ainda a senhora Martinelli, “é também este compromisso ético-politico que deve nos fazer avançar na sistematização das ações e na construção de conhecimentos” (Ibid., p. 29).

\footnotetext{
${ }^{4}$ Ver E. Goulart, pp. 121, 131, 156.

Revista Serviço Social \& Saúde. UNICAMP Campinas, v. X, n. 12, Dez. 2011
} 
Dizer isso, assim, é sugerir que o encontro das atividades do Serviço Social na Saúde, tal qual está posto aqui, aparece como um paradigma “explosivo” das questões mais fundamentais que estão postas hoje, relativas à epistemologia e à deontologia dos conhecimentos das atividades humanas. Acreditamos que haja uma dimensão genérica das questões que nos são postas aqui a propósito do que temos chamado de "tratamento do encontro"

\section{MODELIZAR OU TRATAR OS ENCONTROS?}

Pode-se, ainda, ir além: refletir sobre a qualidade da intervenção no campo do Serviço Social na Saúde nos ajuda a por o dedo numa dificuldade fundamental do processo de conhecimento quando se trata das atividades humanas (as ciências sociais, as ciências humanas e, mais precisamente, as ciências jurídicas). Trata-se da tendência permanente de subestimar o trabalho de tratamento dos encontros, o que se acaba de evocar na parte precedente.

Nós falamos do processo ou do regime de produção de conhecimentos. Nessa matéria, os conhecimentos que se tornaram patrimônio da humanidade se desenvolveram, antes de tudo, no campo das ciências da natureza (a partir do século XVIII): seus princípios epistemológicos aparecem, ainda mais, como modelos, como um ideal do conhecimento com o qual o saber demonstra sua validade, através da operatividade transformadora das tecnologias e da indústria humana...

Um pouco mais tarde, no campo que é, então, o nosso, o das atividades sociais, desenvolve-se, progressivamente, uma profissionalização em relação aos

saberes antecipativos produzidos, pouco a pouco, nas disciplinas acadêmicas. É esse o caso da profissionalização do Serviço Social na Saúde, que se distingue 
progressivamente das práticas e instituições de caridade, de filantropia, de quadros religiosos ou comunitários, laiciza-se e se codifica.

Percurso que de um lado, tem um caráter bastante positivo: definem-se princípios de ação, de direitos, de casos-tipo, de procedimentos de assistência, procedentes do saber jurídico, cívico, político e outros, procedentes do desenvolvimento das ciências médicas e dos saberes sobre as doenças e suas terapêuticas. Esses saberes, para serem gerados e eficazes, são destacados de casos particulares, de encontros, de histórias singulares, ainda mais quando a experiência dessas pôde inspirar sua formulação.

Estamos, então, perante o poder prodigioso dos conceitos, capazes de se destacar, de se “desaderir” da sedução e das urgências do ambiente imediato, para pensar a natureza e a vida em termos mais gerais ou genéricos.

No campo do agir sobre a natureza, tem-se tal desaderência como ferramenta de poderes prodigiosos sobre o mundo. No advento progressivo das sociedades de direito, essa permite organizar a vida social a partir de normas que antecipam e regulam o viver junto, como, no primeiro plano, o sistema jurídico (recordemos que o direito “não faz distinção de pessoa”, que a lei é, felizmente, a mesma para todos e a justiça — Thémis, para os gregos - mantém os olhos vendados). Esse é o campo diversificado das normas antecedentes.

Mas, hoje, podemos medir, também, os inconvenientes e as derivações quando se transfere, sem prudência, o ideal de modelização das ciências da natureza para os territórios percorridos pelas atividades propriamente humanas. Então, se está pronto para subestimar, minimizar ou, ainda, ignorar o que acaba de caracterizar-se como o trabalho de tratamento dos encontros. Pensar em "desaderência”, como nas ciências da natureza, antecipar, normatizar o que é suposto ou o que se deve produzir, 
constitui uma aquisição irreversível da espécie humana. Mas, quando se adota esse modo de pensar, significa, idealmente, que mesmo que não se chegue nunca a tanto, que se faz um esforço para perseguir, expulsar e neutralizar aquilo que os conceitos e os protocolos experimentais arrastaram consigo para a penumbra dos “estigmas” dos vários enraizamentos desses protocolos dentro de circunstâncias e ambientes locais e singulares. Deixar se arrastar pelos estigmas do “aqui e agora” é interditar de pensar a respeito da generalidade do conceito, da universalidade da lei. Um protocolo experimental em física não tem que "tratar o encontro", no sentido de que se faz necessário se instruir positivamente, construir-se um conhecimento patrimonial do que é singular e não reprodutível na experiência. Pelo contrário, deve-se tentar eliminar, à medida do possível, o fato de que a aparelhagem técnica do laboratório, a invenção do sistema de verificação e os pesquisadores em si, tudo isso, enfim, é um encontro em uma situação histórica que não se pode, infelizmente, escapar do espaço e do tempo. É normal que os cientistas se obstinem a tentar expulsar de seus processos de modelização e de experimentação os estigmas desse encontro, trata-se de algo indispensável e, ainda que não cheguem jamais a tanto, é necessário dar-lhes crédito. Porém, em contrapartida, a que perda de qualidade se chegaria se os profissionais do Serviço Social na Saúde, se toda pessoa que quer intervir no campo social, se decidisse por tomar suas decisões a partir dos saberes acadêmicos ou organizacionais, tendo em vista situações-tipo, tomando suas decisões sem levar em conta as vulnerabilidades ou as formas de superação que seus interlocutores, também seres vivos, lhes sugerem aprender implicitamente no decurso de encontros indefinidamente renovados!

Falando de "ciências" humanas, fazendo-se derivar as formações sobre o social através do "treinamento", faz-se surgir uma maneira de tratar o agir humano por meio da mecânica de partículas e de trocas quantificáveis de energia. O prestígio das 
modelizações científicas conduz a tanto. Os elétrons, os planetas não estão em busca de sua saúde, como o está cada ser humano e cada sociedade humana, através de suas contradições e seus conflitos. E se se podem construir protocolos que antecipem uma configuração e um conjunto de movimentos de partículas, ninguém poderia pretender determinar como se constituirá, a saúde para tal ser humano e tal sociedade em certo momento de sua história. A menos, se compartilha certa definição da saúde, aquela desenvolvida com tamanha profundidade pelo médico e filósofo Georges Canguilhem:

A saúde, como expressão do corpo produzido, é uma garantia vivida em duplo sentido: garantia contra o risco a audácia para corrê-lo. É o sentimento de uma capacidade de ultrapassar capacidades iniciais, capacidades de fazer com que o corpo faça o que ele parecia não prometer inicialmente (CANGUILHEM, 2005, p. 43)

Dessa visão de saúde, ninguém pode pretender conhecer o conteúdo sem aprender, também, o que há dela no encontro com o paciente, com o usuário, com seu meio de vida e com os valores com os quais se organiza tal encontro:

Estamos longe da saúde medida por meio de aparelhos. Chamaremos essa saúde: livre, não condicionada, não contabilizada. Essa saúde livre não é um objeto para aquele que se diz ou se crê o especialista da saúde (CANGUILHEM, 2005, p. 44).

Há, então, um verdadeiro “drama” na linguagem: dentro e através das palavras da linguagem, se está, sempre, suscetível de manipulação quando se trata o viver humano como um uso dos saberes e dos conceitos que não seriam válidos senão no mundo físico. Um mal que evoca a senhora Edna Goulart a respeito do excesso de uma linguagem puramente técnica no aprendizado de jovens assistentes sociais: "Como afirma Freire, para que haja diálogo, é preciso ser capaz de 'falar com' ao invés de 
'falar aos outros', de cima para baixo. Essa preocupação de a atividade de linguagem ser utilizada como instrumento de aproximação e não de distanciamento do usuário evidencia o uso particular da palavra como ponte entre sujeitos” (JOAZEIRO, 2008, p. 115). O mesmo drama permite crer que, quando se manipula os conceitos do saber médico, tem-se o suficiente para se decretar quem tem boa saúde e quem não a tem, o que permite ao especialista de técnicas médicas se instituir como perito da saúde dos outros. Por que é possível esse drama que não cessa de se reproduzir sob nossos olhos?

Eis um vasto problema, mas que se limitará, aqui, a se esquematizar a partir de três motivos:

1) Nunca pensamos, como se viu, que seria possível viver juntos, socialmente sem regras e normas, sem saberes formalizados e codificados independentemente e antes que nós, seres humanos, fizéssemos e refizéssemos nossos meios de vida. Todavia, para tratar nossos semelhantes dignamente, como viventes e como cidadãos, tal qual se viu a respeito do Serviço Social, é necessário se decompor, esmiuçar, rearticular e selecionar esses conhecimentos em função daquilo que nos ensinam os usuários sobre sua forma de se superar os riscos da perda da saúde. Esse encontro de saberes, essa “captação”, esse “trabalho” de articulação é, talvez, uma arte, certamente, não uma ciência. Em que momento, então, e até que ponto, é justo fazer uso dos saberes e das normas gerais, formulados em conceitos, e em que momento, enfim, é necessário que se ponham novamente à prova o encontro de histórias de vida nunca semelhantes entre si? Ninguém pode nos dar tal chave, daí o risco permanente, em razão do prestígio do conceito científico, de dar prioridade no primeiro momento, àquele da linguagem em desaderência, em relação ao segundo momento, aquele que leva a se ajustar ao encontro. 
2) É, também, esse prestígio que seduz todas as formas de poder. Um conceito científico se impõe, uma lei física não é discutida sob o ângulo do justo ou do injusto. Usar os procedimentos, as categorias jurídicas e médicas, as prescrições, as palavras da linguagem, como se isso se impusesse sobre nós com a mesma legitimidade que tem um conceito da mecânica ou um protocolo experimental, é, evidentemente, uma inclinação, uma ferramenta temível para se impor objetivos, estratégias e modos de governo do trabalho e dos seres humanos.

Enfim, é mais “reconfortante” governar as atividades humanas “dentro da norma” ao invés de se interrogar constantemente sobre as dramáticas de usos de si mesmo que não cessam de alimentar nossos semelhantes, seus usuários, nos encontros que esses realizam na vida. Daí, então, a tentação permanente de se apoiar sobre os procedimentos e as normas para se ler, governar e antecipar as ocupações produtivas e cotidianas.

A vida humana, porém, não pode se prestar a tal forma de antecipação integral por normas antecedentes. Esses três motivos alimentam uma tentação permanente de se suprimir o que há de mais vital em nós. Mas a vida humana não deixa de renormalizar, de forma visível ou invisível, esse quadro de normas antecedentes. É, por sua vez, impossível e não vivível que os “encontros”, no campo humano e social, não conduzam a renormalizações parciais das normas antecedentes, codificadas em conhecimentos e em prescrições. "Debates de normas”, eis a estrutura principal daquilo que a abordagem ergológica, como estudo da atividade humana, atribui a tal atividade, o que faz toda a diferença com relação à natureza dos seres materiais e físicos.

"Não vivível”: seguindo-se os propósitos já vistos da saúde emprestados acima de G.Canguilhem, se nos é imposta uma definição de nossa saúde oposta ao que 
se chamou anteriormente de uma saúde "livre”, chegamos a ocasiões, como se observa constantemente em situações de trabalho, propícias a nos deixar doentes.

“Impossível”: é o que os ergonomistas, tratando precisamente da atividade, levaram-nos a afirmar quando identificaram, no âmago dos processos taylorianos mais e mais coerções, antecipadas e controladas, formas frequentemente ínfimas, ainda que multiplicadas de “renormalizações”, de gestos e de modos operatórios. Daí a generalização ergológica segundo a qual a pré-estandartização exaustiva das atividades humanas e trabalhistas, ou outras, é impossível (SCHWARTZ,Y; DURRIVE, L., 2003, p. 21-30).

Cremos profundamente que, então, nos é posta uma escolha para qualquer intervenção no campo social, seja profissional ou politicamente. Ou se centraliza em torno de normas antecedentes, daquelas que existem ou daquelas que se deseja criar, com a ideia de que elas determinam, fundamentalmente, o agir humano, ou, por outro lado, intervém-se considerando que haverá, sempre, uma reavaliação dessas normas pelo viver humano, pelo aqui e agora, e que nosso destino é fazer, sempre, parte da dialética de aprendizagem entre o que as normas nos propõem e organizam e o que as renormalizações nos ensinam sobre "a história que se faz". Ou se respeita, afinal, a procura pela saúde que é própria a todos os seres humanos ou se a pretende “domesticar” através, somente, das normas e prescrições já citadas.

“Domesticar”: remete às primeiras páginas de Pedagogia do Oprimido, em que Paulo Freire evoca o duplo sectarismo, de direita e de esquerda. Nos dois casos, a dialética histórica, aquela que faz história através do “esforço de transformação da realidade concreta e objetiva” é, na realidade, “domesticada”, falseada e ilusória. Se se pode “frear”, congelar os processos históricos em um tempo fixo é porque as normas antecedentes e as estruturas econômicas e sociais domesticam a vontade de Revista Serviço Social \& Saúde. UNICAMP Campinas, v. X, n. 12, Dez 2011 
“emancipação do homem”. Porém, pensar que o futuro é predeterminado por estruturas sociais inexoravelmente prefixadas contribui, também, para “formas de ação negadoras da liberdade”, de acordo com a expressão de Paulo Freire, ou, segundo nossa expressão, isso seria ignorar os debates de normas e as dramáticas de usos de si dos seres históricos.

Do ponto de vista da ambição pedagógica, tal domesticação conduz ao que Freire chama de “formação bancária”, cheia de certeza, uma vez que os saberes antecedentes, produzidos na desaderência, não têm, realmente, contas a prestar ao que se aprende nos encontros, sendo, assim, negligenciável.

É preciso, então, deixar esses “círculos de segurança” e não temer “o encontro com o povo"” [termo esse de Freire]. É, exatamente, o que a ergologia chama de necessário “desconforto intelectual”, imposto a todo professor e pesquisador que deseja respeitar aquilo sobre o qual os debates de normas, individuais e coletivos de seus semelhantes, retrabalham saberes e valores que aqueles, tem que conhecer para cumprir sua vocação de transmissão.

Se há debates de normas em todos os nossos agires e, notadamente, no trabalho, e se a respeito deles temos que tomar decisões todos os dias, é porque um universo de valores está intimamente presente em nós e, em nome desses, tomamos tais decisões. "Cada um de nossos atos profissionais, até o menor deles, é dimensionado eticamente, direciona-se à emancipação humana”, disse, com razão, a professora Lúcia Martinelli. E isso é verdadeiro, acima de tudo, no campo da saúde: “área em que pulsam valores humanos candentes, e onde trabalhamos com a vida em suas múltiplas manifestações” (MARTINELLI, 2007, pp. 22-3).

\footnotetext{
${ }^{5}$ Pedagogia do oprimido, Paz e Terra, 45 a edição, 2007, pp. 25-8.

Revista Serviço Social \& Saúde. UNICAMP Campinas, v. X, n. 12, Dez. 2011
} 


\section{3) QUAIS SÃO AS CONSEQUÊNCIAS DE UMA POLÍTICA DE SAÚDE?}

Busquemos resumir o que se acaba de expor:

1) Na profissão do Serviço Social na Saúde, como em toda atividade social, é preciso se produzir e adquirir conhecimentos: em Direito e Legislação Social, em Política Social, em Fundamentos Históricos e Teórico-Metodológicos do Serviço Social, em Administração e Planejamento em Serviço Social, em Formação SócioHistórica do Brasil, em Antropologia, em Psicologia, em Sociologia etc. Há muitos conhecimentos gerais, produtos de uma experiência e de uma inteligência social complexa, que se apresentam em um corpus relativamente independentes, mas coerentes e estruturados.

2) A existência humana, coletiva e individual, recria configurações de vida, sempre, em parte, ressingularizadas. É um usuário que tem certo direito, certa doença e certa situação familiar que o assistente social encontra. Este deve extrair e recombinar pedaços pertinentes desses corpus que lhe foram ensinados separadamente. Em função da importância da afetividade, do nível de recursos do usuário, de sua habitação, aquele deverá ponderar, a cada vez, diferentemente, a importância desses diferentes elementos. Pode haver direitos, mas, também, uma situação familiar tão degradada que não permita que se beneficie desses, obrigando-se a preferir ou a escolher entre certas redes de assistência ou de apoio. O caso apresentado, raramente, faz parte de uma situaçãotipo na qual não há nada além da aplicação dos procedimentos. Memória, inteligência, avaliação e escolha constituem o trabalho desse encontro.

3) Todavia, esse usuário não é um ser passivo, no cruzamento de uma multiplicidade de determinações. Ele está, como todo ser humano, individualmente e coletivamente, sempre à procura de viver seu presente com saúde, aqui e agora. Diante 
das normas antecedentes que estruturam seu meio e lhe imporão, de qualquer forma, sua maneira de viver, o usuário procura sempre, mais ou menos parcialmente, reajustarse ao que pode ter valor para si, a fim de "renormalizar" tais normas. Não se lhe “encontra” como ser vivo humano se não se procura compreender esse esforço de renormalização, que é um esforço de saúde. Instruir-se sobre tal esforço, o que está em permanência reiterada pela profissional do Serviço Social, “faz a experiência” para esta. Assim, em função do que pôde aprender desse esforço de renormalização, essa privilegiará tal recurso legal ou médico, tal terapêutica, tal cuidado a domicílio ou ambulatorial.

Assim, um verdadeiro trabalho de vaivém deve, então, operar-se na pessoa do assistente social: fazer circular nela segmentos de saberes acadêmicos, adquiridos de sua experiência e o que se apreende dia após dia, por “incorporação”, de sua relação face a face com o usuário. É o que se chama "tratar o encontro", o que não tem qualquer equivalente no campo das ciências da natureza.

Quando se toma a medida da intensidade desse trabalho, que nenhum procedimento pode antecipar pode-se questionar, como se sugeriu antes: em quais condições esse trabalho vai se operar sob alta intensidade? Se um trabalho parece mecânico, imagina-se que se possa fazê-lo sem o engajamento da pessoa. Incontestavelmente, não é o caso desses “tratamentos dos encontros”.

Para se engajar em tal tratamento, como em todo engajamento, é necessário valores que se ancoram dentro de nós. Nesse caso, três valores nos parecem aqui, claramente, convocados:

1) O mais geral, o mais genérico, o que indicava a professora L. Martinelli: o usuário é um outro si mesmo para a profissional do Serviço Social, afinal, um 
ser atravessado, como ela, por dramáticas de uso de si, ou ao contrário, uma simples encarnação de categorias médico-sociais?

2) Esse valor genérico toma forma sob uma dimensão mais precisa: no face a face com o usuário, interrogamo-nos sobre o valor saúde, como ele o atravessa? A saúde do Outro tem um preço, não calculável, mas como se dá valor à vida? Eis uma questão na qual não há nada de evidente, considerando o que conhecemos sobre as situações em que os valores mercantis, éticos ou políticos, puderam ou podem aniquilar completamente esse valor saúde, em nosso olhar sobre a vida dos outros.

3) O Serviço Social na Saúde se inclui em um dispositivo de Estado que deve buscar encarnar um Bem Comum. Se um Estado democrático tem sentido, se a igualdade de voto e de voz faz sentido para nós, então, essa igualdade deve poder progredir na vida social. Se a cidadania tem valor, então, não se pode admitir como normal a desigualdade diante da vida e da morte, não se pode aceitar para uma parte dos habitantes ter condições de vida que tornem ilusório o exercício mesmo da cidadania ${ }^{6}$. Assim, o valor “cidadania”, em um estado de direito, é, também, um valor que valoriza a intensidade positiva do tratamento do encontro.

Determina-se, assim, a extrema complicação das relações entre os saberes, os valores e o agir profissional. Alguns nos questionam frequentemente: suas teses sobre o intrincamento entre os valores, os saberes e o agir não são, afinal, mais éticas do que científicas?

\footnotetext{
${ }^{6}$ Ver E. Goulart, op. cit., p. 169. 
Não há resposta simples. Pode-se argumentar, “cientificamente”, que toda atividade humana é, sempre, constituída de debates de normas e que tais debates não podem ser decididos senão por referência a valores não dimensionáveis que extrapolem o aqui e agora. Pode-se, também, pensar que essa é uma escolha axiológica de trabalhar filosoficamente a atividade humana, sob essa abordagem, como matriz da universalidade entre os homens. Ninguém pode dizer qual é a primeira: a preocupação ética ou a preocupação científica. Em todo o caso, é importante reafirmar a exigência de rigor de pensamento antes de se formular quaisquer propostas de conclusão.

Considerar profundamente as situações dos serviços sociais na saúde como encontros, e o agir nas correspondentes profissões como se se tratasse de um trabalho de tratamento desses encontros, terá implicações, em nosso senso, sobre a abordagem das políticas de saúde, as formações que as profissionalizam e as posturas de gestão e de gerenciamento das instituições correspondentes.

Sendo necessário “tratar os encontros”, pode-se dizer que os dispositivos jurídicos, a definição dos beneficiários, as categorias-tipo, as opções terapêuticas são, sempre, passíveis de reavaliação. Reavaliações a partir das renormalizações vivas dos usuários, das famílias, das comunidades. Em todos os níveis das políticas sociais, convém, então, criar o que nós chamamos de “dupla antecipação”: os saberes acadêmicos, codificados, os corpus disciplinares, definindo-se situações-tipo, as regras de cidadania, antecipam, por um lado, os encontros que vão realizar as pessoas dos serviços com os usuários. Porém, por intermédio desses profissionais e de sua experiência acumulada, as renormalizações dessas populações de usuários devem 
antecipar o trabalhar de reavaliação dos dispositivos dos saberes sociais, seus limites, sua rigidez e suas disparidades, com todas as formas de reinvenções sociais nos bairros, nas periferias, nos vilarejos.

Essa exigência da dupla antecipação deve impregnar a concepção das formações profissionais, a fim de preparar as jovens assistentes sociais para tais encontros. “Formar”, e não “treinar”, toma, aqui, todo o seu sentido. Na tese da senhora Edna Goulart, vê-se esta preocupação constante dos supervisores de estágio: manter uma vigilância contínua para operar circulações nunca antes estandardizadas entre o encontro dos usuários com os estudantes bolsistas, os saberes acumulados pela própria experiência dos encontros e seus saberes codificados a partir dos corpus acadêmicos. Subdimensionar essa exigência pela dicotomia “teórica-prática”, sem "revisar tais fronteiras" (JOAZEIRO, 2008, p. 81), conduz a um "sentimento de frustração, impotência” (Ibid., p. 79) . Uma supervisora, sobre essa dicotomia, diz: “eu tenho horror, para dizer a verdade, eu tenho horror desse tipo de discurso”. Não gerir, conscientemente, essa dupla antecipação, pensar que o encontro da realidade está já todo preparado por séries de situações-tipo e procedimentos antecipáveis, é gerar, de fato, uma indisposição profunda na dinâmica pedagógica. Assim, Edna Goulart fala de uma supervisora de estágio: “na sua visão, os saberes da prática não dialogam com os da academia. Há um abismo entre esses lugares”. E o sentimento desse abismo é tamanho que vem para esterilizar o discurso: “no interdito de criar formas de efetivar esse diálogo, o silêncio reina [...]” (Ibid., p. 127).

Enfim, gerir, avaliar somente sob as normas antecedentes, governar as carreiras e o trabalho dos profissionais somente em referência a procedimentos e resultados, que pretendem ignorar a prova e a experiência dos encontros, é, definitivamente, minar, obstruir a intensidade positiva do engajamento no tratamento Revista Serviço Social \& Saúde. UNICAMP Campinas, v. X, n. 12, Dez 2011 
do encontro. Eis um pequeno exemplo assinalado pela senhora Edna Goulart: existe uma norma cara à profissão que determina "preservar as condições ideais para a realização da entrevista como criação de um espaço para o atendimento protegido de ruídos e olhares externos” (Ibid., p. 139). Pois então, há casos, que somente a experiência ensina, em que os riscos de violência contra a assistente social exigem uma infração à norma: deixar-se a porta aberta para se proteger

É aí que se encontra a questão do engajamento e dos valores: se nos cegamos ante a exigência de gerir, na definição das políticas de saúde, ainda mais na concepção das formações ou da gestão de serviços, essa dupla antecipação, então, arrisca-se a produzir uma degradação da qualidade do trabalho e das relações profissionais. Um tratamento dos encontros de alta intensidade positiva supõe, afinal, uma regulação do agir profissional por valores. Não se levar em conta essa intensidade do tratamento dos encontros é encobrir — e então enfraquecer e extenuar — essa regulação pelos valores. Essa grande intensidade no tratamento dos encontros não é fácil, nem evidente para ninguém, e, notadamente, isso exige muito das assistentes sociais. É cansativo, às vezes, esgotante. Na concepção das políticas públicas, das políticas de formação e dos princípios de gestão, negligenciar a necessidade de revisar, constantemente, as normas, em virtude do que impõe a dupla antecipação, é subestimar o tratamento dos encontros e, portanto, os valores de humanidade, de saúde e de cidadania que podem fazer toda a qualidade desse oficio.

Nisso, o campo do Serviço Social na Saúde não é, qualitativamente, distinto de todas as outras profissões e dos outros saberes exercidos no campo das atividades humanas. Todavia, levando-se em conta sua intensidade como lugar de encontros de

\footnotetext{
${ }^{7}$ Abrir ou fechar uma porta, nas situações de trabalho e, sobretudo, nas situações de dedicação, é sempre uma decisão ligada a escolhas de uso de si na realização de uma atividade, mas cujo valor humano remete, sempre, a configurações locais. "Abrir a porta a quem não bateu", F. Pessoa, citado por L. Martinelli (2007, p. 27).

Revista Serviço Social \& Saúde. UNICAMP Campinas, v. X, n. 12, Dez. 2011
} 
atividades humanas, pode-se, legitimamente, dizer que se trata de um paradigma do que se faz necessário pensar para construir bens-comuns no seio de nosso estado de direito.

\begin{abstract}
In this article we discuss what comprises, in the perspective of ergology, "to encounter" human activities, working activities and, more generally, all social activities. The case of the work inside the "social” sector makes evident the problem, in particular. This is done by questioning the permanent tendency of underestimating the encountering treatment efforts on the working activities. We believe that there is a general dimension of the questions posed here about what we have called "encountering treatment". We ask ourselves on the specificity of the "encounters" on working activities of Social Work in Health. In this job the real working activity assumes to encounter an extreme diversity of ways of living and surviving, through a prodigious and sometimes painful cleverness in its manner of producing life. Then, this encountering treatment manifests itself as a plead for capturing the knowledge under the injunction more or less internalized of each social worker, of the health values and of the citizenhood. It is a real job that appears as an "explosive” paradigm of the fundamental questions posed today referring to the epistemology and deontology of human activities knowledge.
\end{abstract}

KEYWORDS: Work, Ergology, Social Work, Public Health

\title{
REFERÊNCIAS BIBILIOGRÁFICAS
}

CANGUILHEM, G. Escritos sobre a Medicina. Rio de Janeiro: Forense

Universitária. 2005, 88 p.

FREIRE, P. Pedagogia do oprimido. São Paulo: Paz e Terra. 45ª edição. 2007. 214 p.

JOAZEIRO, E.M.G. Supervisão de Estágio: formação, saberes, temporalidades. Santo André, SP: ESETec. 2008. 260 p. 
MARTINELLI, M.L. O exercício profissional do assistente social na área da saúde: algumas reflexões éticas. Serviço Social \& Saúde, ano VI, nº 6, 2007, pp. 22-33.

ROSA, M.I. Usos de si e testemunhos de trabalhadores: Com estudo crítico da Sociologia Industrial e da Reestruturação Produtiva, São Paulo: Letra \& Letras, 2004.

SCHWARTZ, Y. ; DURRIVE, L. Travail et Ergologie, entretiens sur l’activité humaine. Toulouse: Octarès Editions, 2003, pp. 21-30. 